\title{
Improving the Performance of Mass-Consistent Numerical Models Using Optimization Techniques
}

J. C. Barnard

H. L. Wegley

T. R. Hiester

September 1985

Prepared for the U.S. Department of Energy under Contract DE-AC06-76RLO 1830

Pacific Northwest Laboratory Operated for the U.S. Department of Energy by Battelle Memorial Institute 


\title{
DISCLAIMER
}

This report was prepared as an account of work sponsored by an agency of the United States Government. Neither the United States Government nor any agency thereof, nor any of their employees, makes any warranty, express or implied, or assumes any legal liability or responsibility for the accuracy, completeness, or usefulness of any information, apparatus, product, or process disclosed, or represents that its use would not infringe privately owned rights. Reference herein to any specific commercial product, process, or service by trade name, trademark, manufacturer, or otherwise, does not necessarily constitute or imply its endorsement, recommendation, or favoring by the United States Government or any agency thereof. The views and opinions of authors expressed herein do not necessarily state or reflect those of the United States Government or any agency thereof.

\author{
PACIFIC NORTHWEST LABORATORY \\ operated by \\ BATTELLE \\ for the \\ UNITED STATES DEPARTMENT OF ENERGY \\ under Contract DE-AC06-76RLO 1830
}

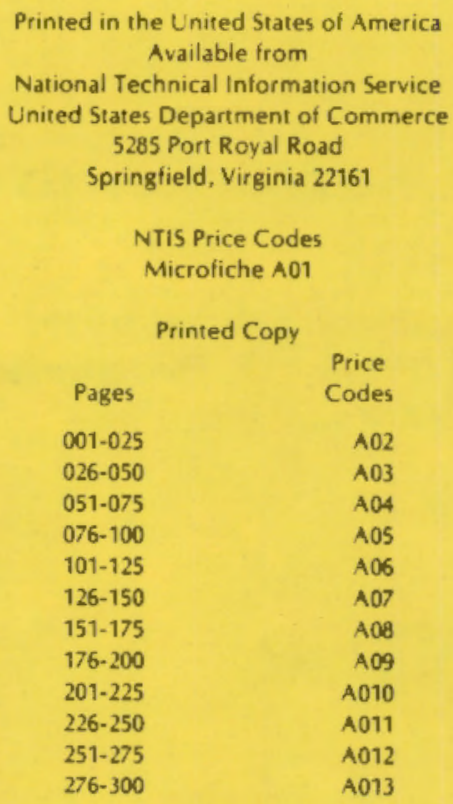


IMPROVING THE PERFORMANCE OF MASS-CONSISTENT NUMERICAL MODELS USING OPTIMIZATION TECHNIQUES
J. C. Barnard
H. L. Wegley
T. R. Hiester (a)

September 1985

Prepared for the U.S. Department of Energy under Contract DE-AC06-76RLO 1830

Pacific Northwest Laboratory

Richland, Washington 99352

\footnotetext{
(a) Flowind Corporation

Pleasanton, California 94566
} 


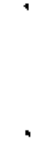




\section{SUMMARY}

This report describes a technique of using a mass-consistent model to derive wind speeds over a microscale region of complex terrain. A serious limitation in the use of these numerical models is that the calculated wind field is highly sensitive to some input parameters, such as those specifying atmospheric stability. Because accurate values for these parameters are not usually known, confidence in the calculated winds is low.

However, values for these parameters can be found by tuning the model to existing wind observations within a microscale area. This tuning is accomplished by using a single-variable, unconstrained optimization procedure that adjusts the unknown parameters so that the error between the observed winds and model calculations of these winds is minimized.

Model verification is accomplished by using eight sets of hourly averaged wind data. These data are obtained from measurements made at approximately 30 sites covering a wind farm development in the Altamont Pass area. When the model is tuned to a small subset of the 30 sites, an accurate determination of the wind speeds was made for the remaining sites in six of the eight cases. (The two that failed were low wind speed cases.) Therefore, when this technique is used, numerical modeling shows great promise as a tool for microscale siting of wind turbines in complex terrain. 



\section{CONTENTS}

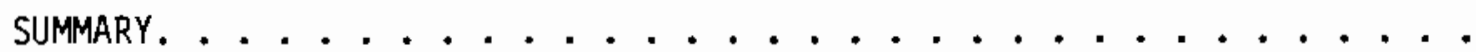

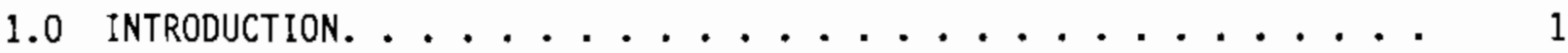

2.0 A NEW TECHNIQUE FOR USING MASS-CONSISTENT MODELS FOR WIND FIELD

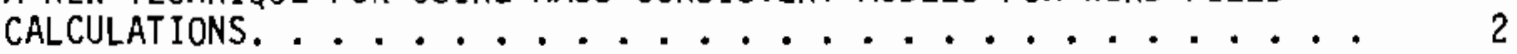

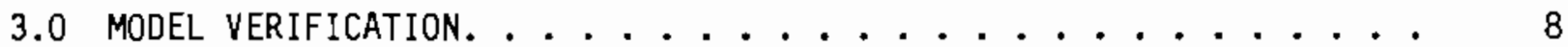

3.1 DATA USED IN VERIFICATION. ................ 8

3.2 EXPERIMENTAL TECHNIQUE . . . . . . . . . . . 10

3.3 RESULTS. . . . . . . . . . . . . . 11

4.0 FURTHER RESEARCH. . . . . . . . . . . . . . . 17

5.0 RefERENCES. ............................. 18

APPENDIX: MODEL VERIFICATION RESULTS FOR EIGHT WIND CASES EXAMINED. . . A-1 
FIGURES

2.1 Sensitivity of RMSE to Stability and Wind Direction. ..... 5

2.2 Sensitivity of RMSE to Stability ........... 6

$3.120-F t$ Terrain Contours and Data Site Locations . . . . . 10

3.2 Tuning and Verification Site Observed Versus Modeled

Wind-Speed Ratios for the Six Well-Tuned Cases . . . . . . 13

3.3 Discrimination Criterion for Well-Tuned and Poorly Tuned

Cases Based Upon Linear Regression of A11 8 Cases. . . . . . 14

3.4 Typical Well-Tuned Flow Model Results (Case 3A). . . . . 15

3.5 A Typical Case Demonstrating Poorly Tuned Flow Model Results

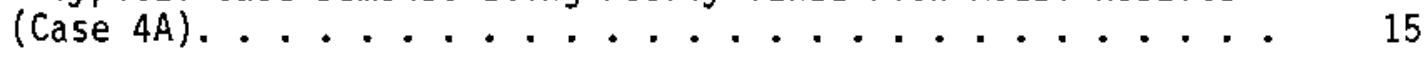

3.6 Stability $(\log \tau)$ Versus Time of Day . . . . . . . 16

A.1 Scatter Piot of Observed Versus Model-Calculated Wind

Speed Ratios for Case 2A . . . . . . . . . . . A-2

A.2 Scatter Plot of Observed Versus Model-Calculated Wind

Speed Ratios for Case 2B ............. A-2

A.3 Scatter Plot of Observed Versus Model-Calculated Wind

Speed Ratios for Case 3A . . . . . . . . . . A A-3

A.4 Scatter Plot of Observed Versus Model-Calculated Wind

Speed Ratios for Case 3B ............. A-3

A.5 Scatter Plot of Observed Versus Model-CalcuTated Wind

Speed Ratios for Case 4A ............ A-4

A.6 Scatter Plot of Observed Versus Model-Calculated Wind

Speed Ratios for Case 4B............... A-4

A.7 Scatter Plot of Observed Versus Model-Calculated Wind

Speed Ratios for Case 5A ............ A-5

A.8 Scatter Plot of Observed Versus Model-Calculated Wind

Speed Ratios for Case $5 B \ldots \ldots$ A-5 


\section{TABLES}

3.1 Wind Data Used for Model Verification. . . . . . . .

3.2 RMS Error and Correlation Coefficients for Tuning Sites. .

3.3 RMS Error and Correlation Coefficients for Verification 


\subsection{INTRODUCTION}

During the past five years, commercial wind energy development has accelerated rapidly in portions of the United States. Development has been concentrated in wind farms (clusters of wind turbines) that are often located in complex terrain. In such terrain large variations in energy production can resuit from fluctuations in wind that occur over relatively small distances (50 to $100 \mathrm{~m}$ ). Wind energy development has thus generated a need for smali-scale or "micrositing" tools that would identify high wind speeds over areas the size of a wind farm (about $10 \mathrm{~km}^{2}$ or $2 \mathrm{mi}^{2}$ ). The tools must provide sufficient resolution of the wind flow over the area in three-dimensional space to discriminate clearly between suitable and unsuitable sites.

This report describes a new technique for using a mass-consistent numerical flow model as a micrositing tool. Past attempts to use such numerical models have often produced questionable, or poor, results because accurate flow simulation depends in part upon model input parameters that have been provided by educated (but often erroneous) guesswork. However, it is hypothesized here that if simultaneous short-term wind measurements are available for a small number of locations in an area of interest, a single-variable, unconstrained optimization technique can be used to calculate the important flow model parameters using available wind data. This technique should provide accurate wind-flow predictions over the entire area of interest and should not require more extensive wind data than those that would normally be collected during the wind prospecting phase of turbine siting. Studies by Kitada et al. (1983) suggest that complex flow conditions can be accurately represented using limited observed data.

Section 2 of this report provides a conceptual description of the mathematical optimization scheme and how it is used in the flow model. In Section 3 verification results for the model are presented and discussed. Recommendations for further development of an accurate micrositing tool are made in Section 4. Detailed verification data are contained in an appendix to the report. 


\subsection{A NEW TECHNIQUE FOR USING MASS-CONSISTENT MODELS FOR WIND FIELD CALCULATIONS}

Atmospheric flow models vary greatly in complexity. Among the more simple of these are the so-called "mass-consistent" models. For a given area, these models take known observations of the wind at specific places and use these observations to calculate a wind field throughout the modeling domain. In this way, the wind can be estimated at places away from the wind observation sites. The simplicity of these models makes them attractive for wind energy purposes, as they do not require much input data, and they are easy and economical to operate.

Sherman (1978) describes the theory of the mass-consistent model. Known observations of the wind are used to construct an initial guess of the wind at every grid point in the modeled area. These initial winds are then adjusted to achieve a final wind field that satisfies the equation of mass continuity (hence the name mass-consistent model). The adjustment at grid points adjacent to solid boundaries is done so that the adjusted wind field is parallel to the boundary. Because these two features of the adjustment are important influences on wind flow in complex terrain, the mass-consistent model is particularly suited for flow simulations in such areas.

Another important feature of the adjustment is the relative weight given the adjustment in the horizontal and vertical directions. This weight is not a direct measure of atmospheric stability; rather, it is used in the model to simulate atmospheric stability and is given the symbol $\tau$. Specifically, $\tau$ is the ratio of the vertical adjustment to the horizontal adjustment. Values of $\tau$ close to 1.0 imply a neutral atmosphere; the flow adjustment is not given preference in either the horizontal or vertical direction. Values of $\tau$ much less or greater than 1.0 imply stable or unstable atmospheres, respectively. The stability is important since the calculated winds are quite sensitive to the value of $\tau$ specified as input to the model.

Mass-consistent models have not been adequately tested to assure their suitability for wind energy purposes. Two difficulties have caused this situation: The first difficulty is that spatially dense verification data sets 
have not been avajlable, particularly for microscale regions. The second difficulty is more subtle. Besides the wind observations and terrain data required for model input, one must also specify the atmospheric stability parameter $\tau$. Model-calculated winds are quite sensitive to this parameter and even approximate values for it are usually not known. This occurs because $\tau$ cannot be physically related to common measures of the stability such as the vertical temperature gradient. Even if an empirical relationship can eventualiy be developed, temperature soundings are rarely available near the site in question. Kitada et al. (1983) discuss the sensitivity of calculated flow fields to the stability.

Since model-calculated winds are sensitive to the stability and appropriate values for it can only be guessed, confidence in calculated winds has been low. The technique to be described circumnavigates the need for a priori knowledge of the stability. Instead of being an input parameter, it becomes a calculated quantity.

The technique merges an existing mass-consistent model with an optimization procedure. (This combination will henceforth be referred to as the "model"). The model requires as input a number of wind observations over the microscale area of interest. These observations are known as "tuning" sites. One of these tuning sites is designated as the reference site and is used to initialize the model. The optimization procedure is then used to vary $\tau$ (and the wind direction of the reference site) until the error between the calculated and observed winds at the tuning sites is minimized. If this error is smal1, then model-derived estimates of the wind away from the wind observations should be good. The results shown later in Section 3 confirm that, when the error between calculated and observed winds at the tuning sites is small, the accuracy of model-estimated winds is high.

A mathematical description of this optimization is as follows. Assume that there are $\mathrm{N}$ wind observation sites distributed over a microscale region. (For the verification studies described later, $N$ ranges from 6 to 8.) The station with the highest average wind speed is designated as the reference site. For a given averaging period (hourly averaged data are used in this 
report), the wind speeds are normalized by the reference site wind speed. This gives a set of ratios $r_{i}{ }^{0}$ for each set of (hourly) averaged wind data, where the subscript $i$ denotes the station $i$ and 0 denotes that these are observed ratios. The reference site $(i=1)$ speed is normalized by itself so that $r_{i}{ }^{0}=1$.

A corresponding set of calculated ratios can be derived by operating the model with a given set of input data and then normalizing the calculated speeds of the tuning sites by the calculated speed at the reference site. These ratios are denoted by $r_{i}{ }^{c}$ (where $c$ denotes calculated ratio); they are considered a function of only the atmospheric stability $\tau$, and the input wind direction $\theta$. The input wind direction is included since it was only crudely specified in the wind data used in this study, and variations about the given direction were sometimes observed to cause large changes in $r_{i}{ }^{c}$.

It is not necessary to restrict the dependence of $r_{i}{ }^{c}$ to just stability and wind direction. Other parameters could also be included. The important point is to include those parameters for which the ratios $\mathbf{r}_{\boldsymbol{j}}{ }^{\mathrm{C}}$ show greatest sensitivity. Initial testing has indicated that the calculated ratios are most sensitive to $\tau$ and $\theta$. To show the explicit dependence of $r_{i}{ }^{c}$ on these quantities, they will be written as $r_{j}{ }^{c}(\tau, \theta)$.

A measure of the goodness of fit between the calculated and observed ratios is the root mean square error, RSME, given by the expression

$$
\operatorname{RSME}(\tau, \theta)=\left[\sum_{c=2}^{N} r_{i}{ }^{0}-r_{i}{ }^{c}(\tau, \theta){ }^{2} /(N-1)\right]^{1 / 2}
$$

Since the calculated ratios $r_{j}{ }^{c}(\tau, \theta)$ depend upon $\tau$ and $\theta$, the error is also a function of these quantities as is explicitly indicated above (the sum in the above expression does not include the reference site $i=l$ since $i t$ does not contribute to the error).

The root mean square error can be depicted as a three-dimensional surface. For one of the data sets used in this study, this surface is shown in Figure 2.1. The abscissae for this figure are the wind direction and the log 


\section{- - MINIMUM RMSE (.038) \\ LOG[STAPILITY] $=-.2$ \\ WIND DIRECTION - 238 DEGREES}

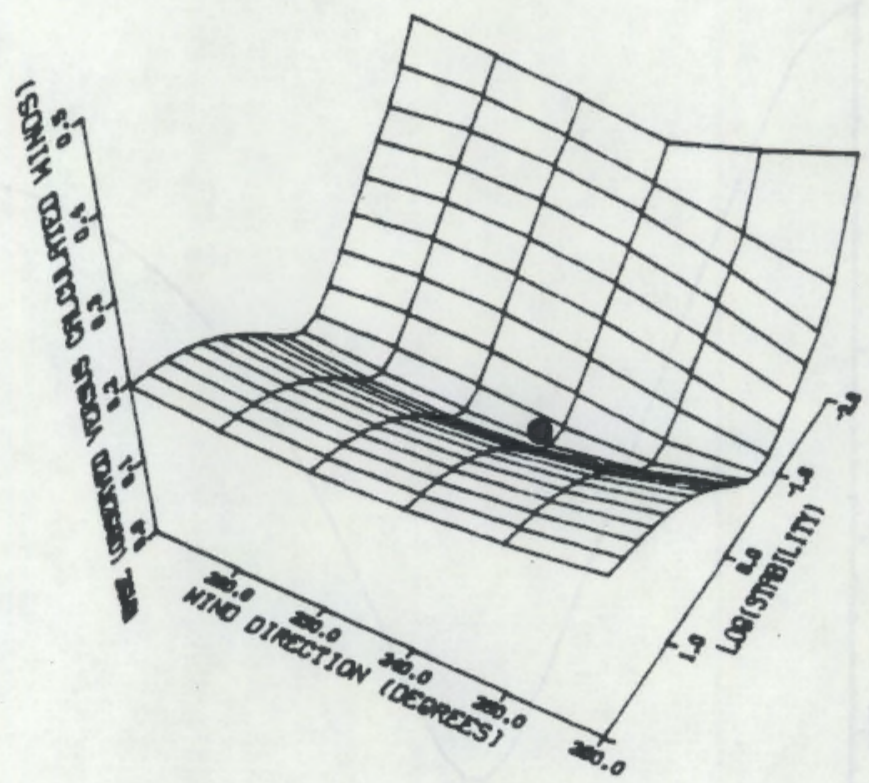

FIGURE 2.1. Sensitivity of RMSE to Stability and Wind Direction

of the stability $(\log (\tau))$, which ranges from -2 (stable) through 0 (neutral) to +2 (unstable). Figure 2.1 shows that for this particular data set the root mean square error is much more sensitive to changes in $\tau$ than to changes in the wind direction. (To better illustrate the sensitivity of $\operatorname{RMSE}(\tau, \theta)$ to stability, Figure 2.2 shows $\operatorname{RSME}(\tau, \theta)$ as a function of $\log (\tau)$ for a fixed value of $\left.\theta,\left(238^{\circ}\right)\right)$.

The "best fit" of the observed and calculated ratios is obtained when $\operatorname{RSME}(\tau, \theta)$ is a minimum. The error is minimized in practice by making initial guesses of $\tau$ and $\theta$ and then using a single variable, unconstrained optimization technique (applied twice) to find the optimum values of these parameters; that is, the values of $\tau$ and $\theta$ when $\operatorname{RMSE}(\tau, \theta)$ is a minimum. This method is very 


\section{CASE 3B - FALL DATA}

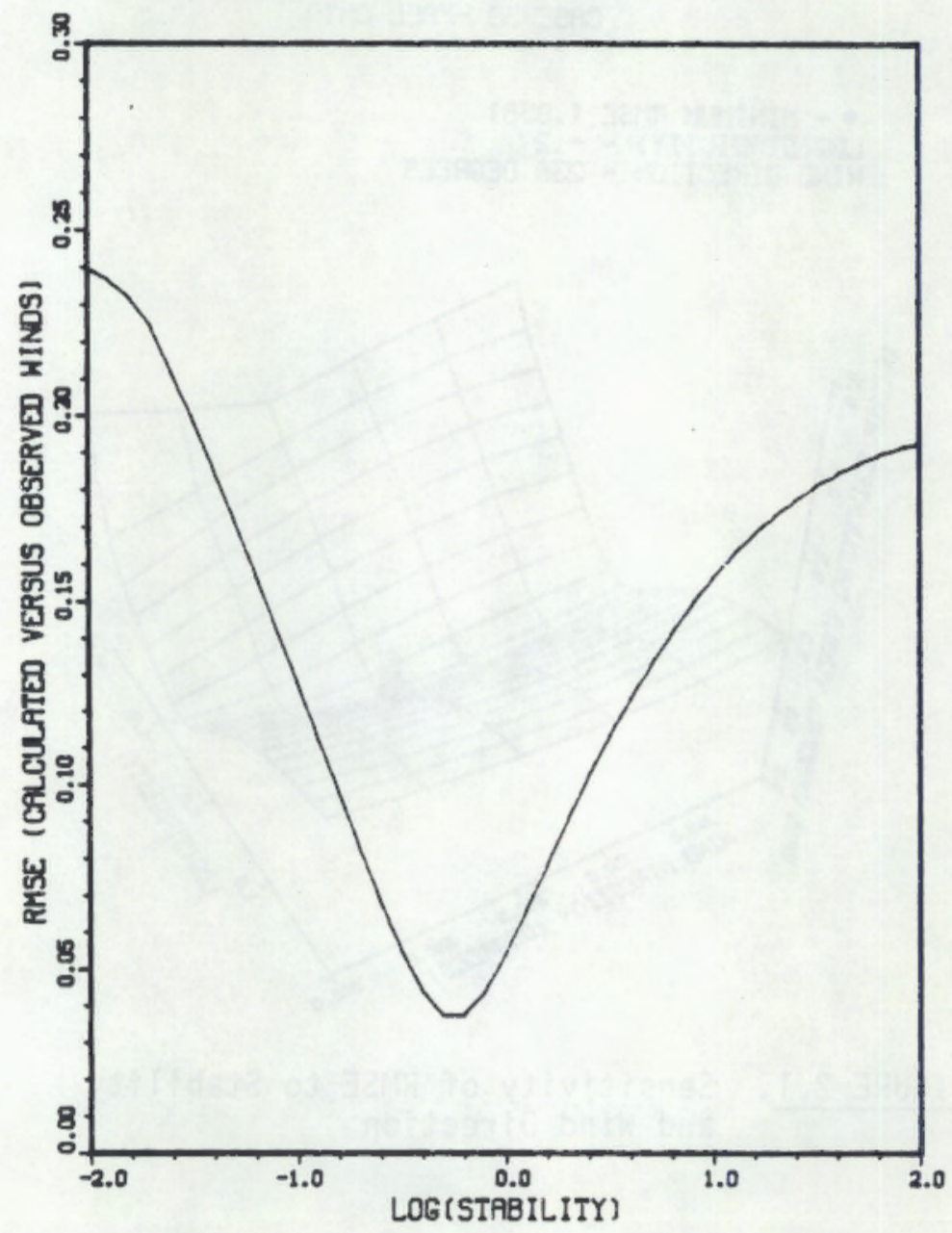

FIGURE 2.2. Sensitivity of RMSE to Stability

similar to the Coggin algorithm (Kuester and Mize 1973). For the data depicted in Figure 2.1, the minimum error occurs for $\log (\tau)=-0.2$ and $\theta=238^{\circ}$. This minimum point is indicated by the black dot on the surface. About 1 hour of VAX $11 / 780$ computer time is required for the minimization procedure.

In summary, this technique minimizes the error between wind observations and model calculations of the wind at the tuning sites. This minimization is a function of two variables: $\tau$ and $\theta$. If the minimum error is sufficiently small, the results in the next section show that estimates of the wind ratios 
away from the observation sites are good, and a priori knowledge of the stability parameter is no longer necessary.

The mass-consistent model that was merged with the optimization scheme is the NOABL model. This mass-consistent model was developed for the U.S. Department of Energy by Science Applications, Inc. A description of the model is contained in a report by Traci et al. (1978). 


\subsection{MODEL VERIFICATION}

In this section the data set used in the verification is described, the experimental technique used is presented, and results are discussed.

\subsection{DATA USED IN VERIFICATION}

Data available for the verification of the flow model consisted of hourly averaged wind speed and direction at 1 reference site and simultaneous hourly averaged wind speeds for up to 27 other sites. These data were collected for the 8 cases shown in Table 3.1. Wind directions are all from the southwest quadrant (225 to $250^{\circ}$ ), the prevailing power-producing wind direction for the area. The speeds vary from light to moderate (10 to $19 \mathrm{mph}$ in Case $2 \mathrm{~B}$ ) to very strong (22 to $44 \mathrm{mph}$ in Case $3 \mathrm{~A}$ ).

Atmospheric stability (inferred from wind speed and time of day) appears to vary somewhat over the 8 cases. Cases $4 B$ and $5 B$ represent moderate and strong nighttime winds, respectively; Cases $2 A$ and $3 A$ represent moderate and strong afternoon winds, respectively; and Cases $4 \mathrm{~A}$ and $5 \mathrm{~A}$ represent moderate and strong evening winds, respectively. Thus, the data set tests to some degree the selection of appropriate stability parameters by the optimization scheme.

Figure 3.1 presents the terrain configuration and the location of the data sites for the verification of the flow model. The terrain, represented by the $20-\mathrm{ft}$ contours in the figure, is based upon a $40-\mathrm{by}-40$ grid of terrain heights spaced evenly at $50-m$ intervals. The flow model run time increases exponentially with grid size. The $50-\mathrm{m}$ grid interval was a subjectively selected value based upon an attempt to minimize the number of grid points and yet retain enough terrain resolution to represent the features that might affect the wind flow over the area. (The selection of optimal grid spacing can be made much more objective after sensitivity testing of verified model results to grid interval is accomplished.) 
TABLE 3.1. Wind Data Used for Model Verification

\section{Case Descriptions}

\begin{tabular}{|c|c|c|c|c|}
\hline Case & & -Time & \multicolumn{2}{|c|}{$\begin{array}{ll}\text { Wind at Reference Site } \\
\text { Speed } & \text { Direction } \\
\text { (mph) } & \left({ }^{\circ}\right) \\
\end{array}$} \\
\hline $\begin{array}{l}2 A \\
2 B \\
3 A \\
3 B \\
4 A \\
4 B \\
5 A \\
5 B\end{array}$ & $\begin{array}{ll}\text { Oct } & 30 \\
\text { Nov } & 13 \\
\text { Oct } & 26 \\
\text { Nov } & 2 \\
\text { Oct } & 27 \\
\text { Nov } & 1 \\
\text { Oct } & 26 \\
\text { Nov } & 13\end{array}$ & $\begin{array}{l}1500-1600 \\
1100-1200 \\
1400-1500 \\
1500-1600 \\
1900-2000 \\
2300-2400 \\
1900-2000 \\
0200-0300\end{array}$ & $\begin{array}{l}22 \\
19 \\
44 \\
41 \\
19 \\
22 \\
38 \\
41\end{array}$ & $\begin{array}{l}250 \\
240 \\
225 \\
240 \\
240 \\
250 \\
230 \\
235\end{array}$ \\
\hline
\end{tabular}

Site Ref. Number

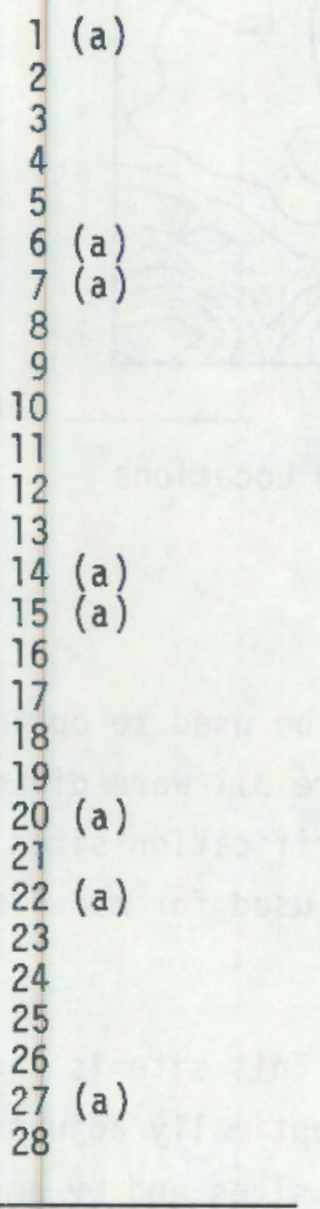

\begin{tabular}{|c|c|c|c|c|c|c|c|}
\hline & & Wind & beeds & & Case & & \\
\hline $2 A$ & $\underline{2 B}$ & $3 A$ & $3 B$ & $4 \hat{A}$ & $\underline{4 B}$ & $5 A$ & $5 B$ \\
\hline 22 & 19 & 44 & 41 & 19 & 22 & 38 & 41 \\
\hline 0 & 12 & 29 & 25 & 18 & 15 & $2 B$ & 20 \\
\hline 16 & 10 & 24 & 23 & 14 & 20 & 25 & 21 \\
\hline & 11 & 27 & 24 & 15 & 20 & 27 & 21 \\
\hline 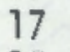 & 12 & 22 & 31 & 19 & 17 & 31 & 23 \\
\hline 19 & 13 & 30 & 27 & 17 & 21 & 28 & 24 \\
\hline 19 & 13 & 31 & 28 & 21 & 20 & 30 & 24 \\
\hline 21 & 14 & 35 & 31 & 22 & 20 & 33 & 27 \\
\hline & $=-$ & 32 & 29 & 19 & 20 & 31 & $=$ \\
\hline 7 & 10 & 24 & 22 & 14 & 18 & 23 & 18 \\
\hline 17 & 11 & 25 & 23 & 14 & 20 & 25 & 21 \\
\hline 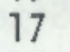 & 10 & 26 & 22 & 15 & 17 & 25 & 16 \\
\hline 15 & 11 & 25 & 23 & 12 & 19 & 25 & 21 \\
\hline 17 & 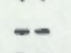 & 29 & 26 & 12 & 17 & 25 & -- \\
\hline 18 & 12 & 27 & 26 & 16 & 19 & 26 & 20 \\
\hline 6 & 12 & 25 & 24 & 15 & 17 & 26 & 23 \\
\hline 17 & 12 & 27 & 24 & 15 & 17 & 27 & 21 \\
\hline 17 & 14 & 29 & 28 & 16 & 17 & 28 & 27 \\
\hline 16 & 14 & 30 & 28 & 11 & 17 & 26 & 27 \\
\hline & 14 & -- & 30 & -- & 17 & -- & 28 \\
\hline 18 & 13 & -- & 31 & -- & 16 & -- & 27 \\
\hline 17 & -- & 34 & 30 & 11 & 16 & 28 & - \\
\hline 20 & 16 & - & 33 & -- & 20 & 32 & 32 \\
\hline 18 & 16 & 35 & 30 & 16 & 18 & 30 & 28 \\
\hline & 13 & 34 & 32 & 16 & 16 & 30 & 28 \\
\hline $1 c$ & 17 & 40 & 35 & 15 & 18 & 32 & 38 \\
\hline 21 & 19 & 44 & 39 & 19 & 20 & 36 & 36 \\
\hline & 17 & 42 & 35 & 18 & 18 & 33 & 34 \\
\hline
\end{tabular}

(a) Tuning sites - Site 1 is the reference site. 


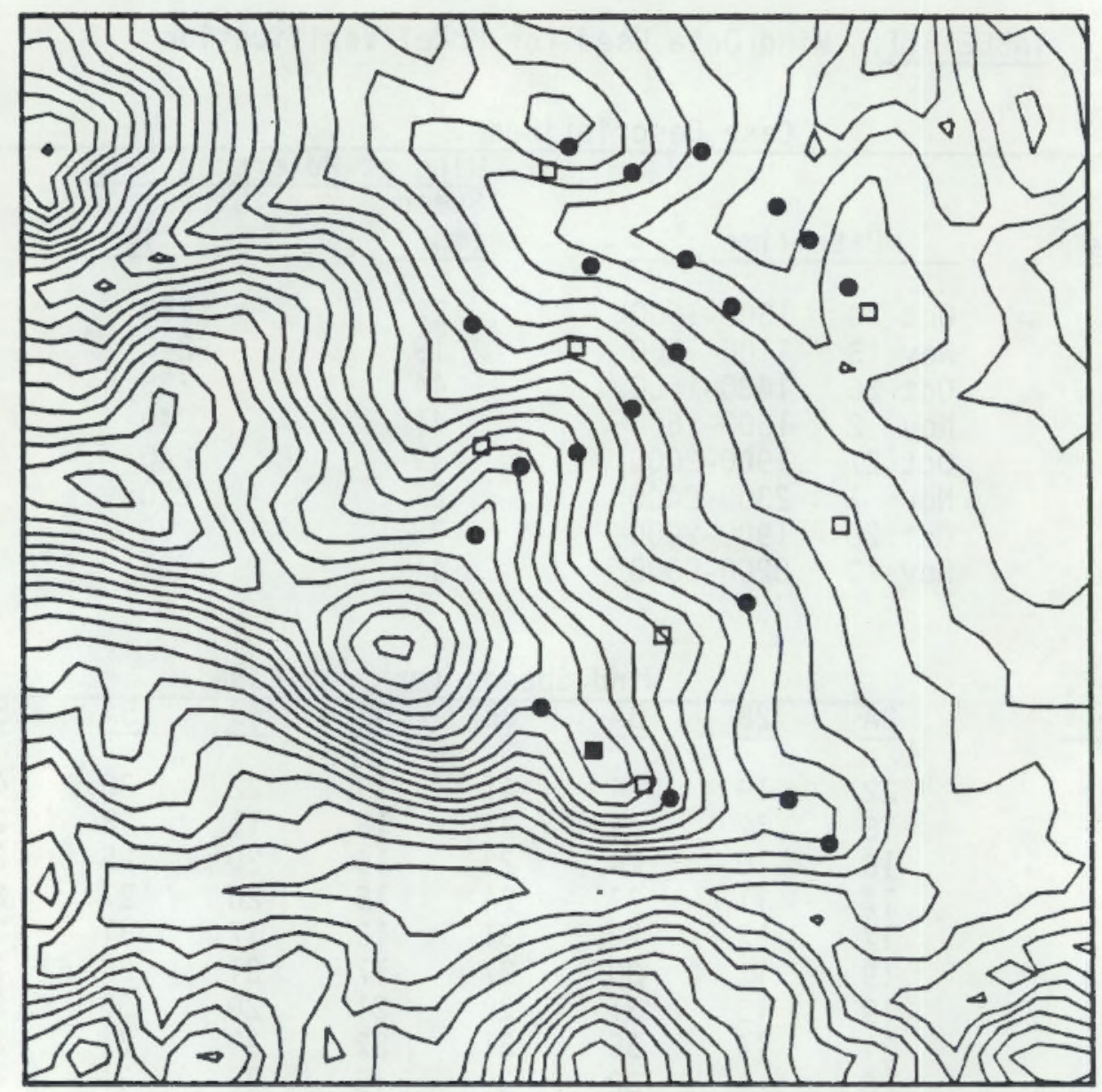

$-1000 \mathrm{ft}$

FIGURE 3.1. 20-Ft Terrain Contours and Data Site Locations

\subsection{EXPERIMENTAL TECHNIQUE}

To test the hypothesis that 1 imited observations can be used to optimize the choice of flow model parameters, the 28 sites in Figure 3.1 were divided into a set of 8 tuning sites (shown as squares) and 20 verification sites (shown as filled circles). Table 3.1 summarizes the data used for model testing and verification.

One tuning site was selected as the reference site. This site is shown as a filled square in Figure 3.1. Model parameters were optimally adjusted for each of the 8 cases using all or most of the 8 tuning sites and by employing the optimization procedure described in Section 2. In 2 of the 8 cases, only 6 of the tuning sites were available and in 3 of the 8 cases, only 7 
tuning sites were available. Based upon the results described later in this section, the variation in the number of sites available for optimizing (from 6 to 8 ) had no noticeable effect upon the model performance. A lower bound on the number of sites required to adequately tune the model for a given terrain area has not yet been established.

To create a set of calculated data for model verification, the optimally adjusted three-dimensional flow field for each case was saved. Each flow field was used to interpolate in three dimensions to obtain wind speeds for the verification sites. Since many wind farm developers have come to use wind-speed ratios (to a reference site), speed ratios were calculated using Site 1 in Table 3.1 as the reference site.

\subsection{RESULTS}

The results of the model tuning procedure for the 8 wind cases examined are presented in Table 3.2. Correlation coefficients $\left(r^{2}\right)$ and root mean square errors (RMSEs) were used as measures of the goodness of fit of the modeled to observed wind-speed ratios. The correlation coefficient represents the fraction of the variance in the observed wind-speed ratios that is explained by the model-produced wind-speed ratios.

TABLE 3.2. RMS Error and Correlation Coefficients for Tuning Sites

\begin{tabular}{|c|c|c|c|c|}
\hline \multirow[b]{2}{*}{ Case } & \multicolumn{2}{|c|}{ Case Description } & \multirow[b]{2}{*}{$\begin{array}{c}\text { R-Squared } \\
(\%)\end{array}$} & \multirow[b]{2}{*}{$\begin{array}{l}\text { RMSE of } \\
\text { Ratios } \\
\end{array}$} \\
\hline & Time & $\begin{array}{c}\operatorname{Dir}\left({ }^{\circ}\right) / \\
\text { Speed (mph) } \\
\end{array}$ & & \\
\hline $2 A$ & Day & $250 / 22$ & 72.4 & 0.042 \\
\hline $2 B$ & Day & $240 / 19$ & 92.3 & 0.042 \\
\hline $3 A$ & Day & $225 / 44$ & 90.9 & 0.045 \\
\hline $3 B$ & Day & $240 / 41$ & 93.8 & 0.034 \\
\hline $4 A$ & Eve & $240 / 19$ & 5.45 & 0.126 \\
\hline $4 \mathrm{~B}$ & Night & $250 / 22$ & 39.8 & 0.075 \\
\hline $5 A$ & Eve & $230 / 38$ & 84.7 & 0.048 \\
\hline $5 B$ & Night & $235 / 41$ & 91.0 & 0.056 \\
\hline \multicolumn{3}{|c|}{ All 8 Cases } & 80.0 & 0.065 \\
\hline \multicolumn{3}{|c|}{6 Cases (excluding $4 A$ and $4 B$ ) } & 90.7 & 0.044 \\
\hline
\end{tabular}


Two of the 8 cases shown in the table, Cases $4 A$ and $4 B$, exhibit a relatively poorer fit to the observed data. Implications of this lack of fit, or poor tuning of the model, are discussed later in this section.

Wind direction data were only available for the reference site; consequently, quantitative verification of the model-calculated directions is not presented. However, the model-derived directions appear realistic over the entire grid, and they agree well with the observed direction at the reference site.

Table 3.3 contains the complete verification data for all 8 cases examined. Comparison of these data with the tuning site data in Table 3.2 reveals that there is a slight deterioration in accuracy for the 6 well-tuned cases; however, there is a much larger deterioration for the 2 poorly tuned cases (4A and $4 B$ ). A comparison of the 6 cases, excluding $4 A$ and $4 B$, shows that the overall RMSE for the verification sites is reduced to 0.037 . This value is smaller than that for any individual case, which is expected since random errors between model-calculated winds and wind observations tend to cancel when averages are

TABLE 3.3. RMS Error and Correlation Coefficients for Verification Sites

\begin{tabular}{|c|c|c|c|c|}
\hline \multirow[b]{2}{*}{ Case } & \multicolumn{2}{|c|}{ Case Description } & \multirow[b]{2}{*}{$\begin{array}{c}\text { R-Squared } \\
(\%)\end{array}$} & \multirow[b]{2}{*}{$\begin{array}{r}\text { RMSE of } \\
\text { Ratios }\end{array}$} \\
\hline & Time & $\begin{array}{c}\operatorname{Dir}\left({ }^{\circ}\right) / \\
\text { Speed (mph) }\end{array}$ & & \\
\hline $2 \mathrm{~A}$ & Day & $250 / 22$ & $13.1^{(a)}$ & 0.080 \\
\hline 28 & Day & $240 / 19$ & 91.3 & 0.060 \\
\hline $3 A$ & Day & $225 / 44$ & 84.8 & 0.074 \\
\hline $3 B$ & Day & $240 / 41$ & 81.0 & 0.050 \\
\hline $4 \mathrm{~A}$ & Eve & $240 / 19$ & 12.3 & D. 175 \\
\hline $4 B$ & Night & $250 / 22$ & 22.7 & 0.154 \\
\hline $5 \mathrm{~A}$ & Eve & $230 / 38$ & 62.3 & 0.047 \\
\hline $5 B$ & Night & $235 / 41$ & 78.0 & 0.067 \\
\hline Al1 & & & 48.2 & 0.099 \\
\hline $6 \mathrm{C}$ & luding & and 48 ) & 81.2 & 0.037 \\
\hline
\end{tabular}

(a) The low R-squared is caused by a single outlying point. 
taken. Figure 3.2, a scatter plot of observed versus modeled ratios for the 6 well-tuned cases, clearly demonstrates the skill of the flow model when proper values of the input parameters are selected.

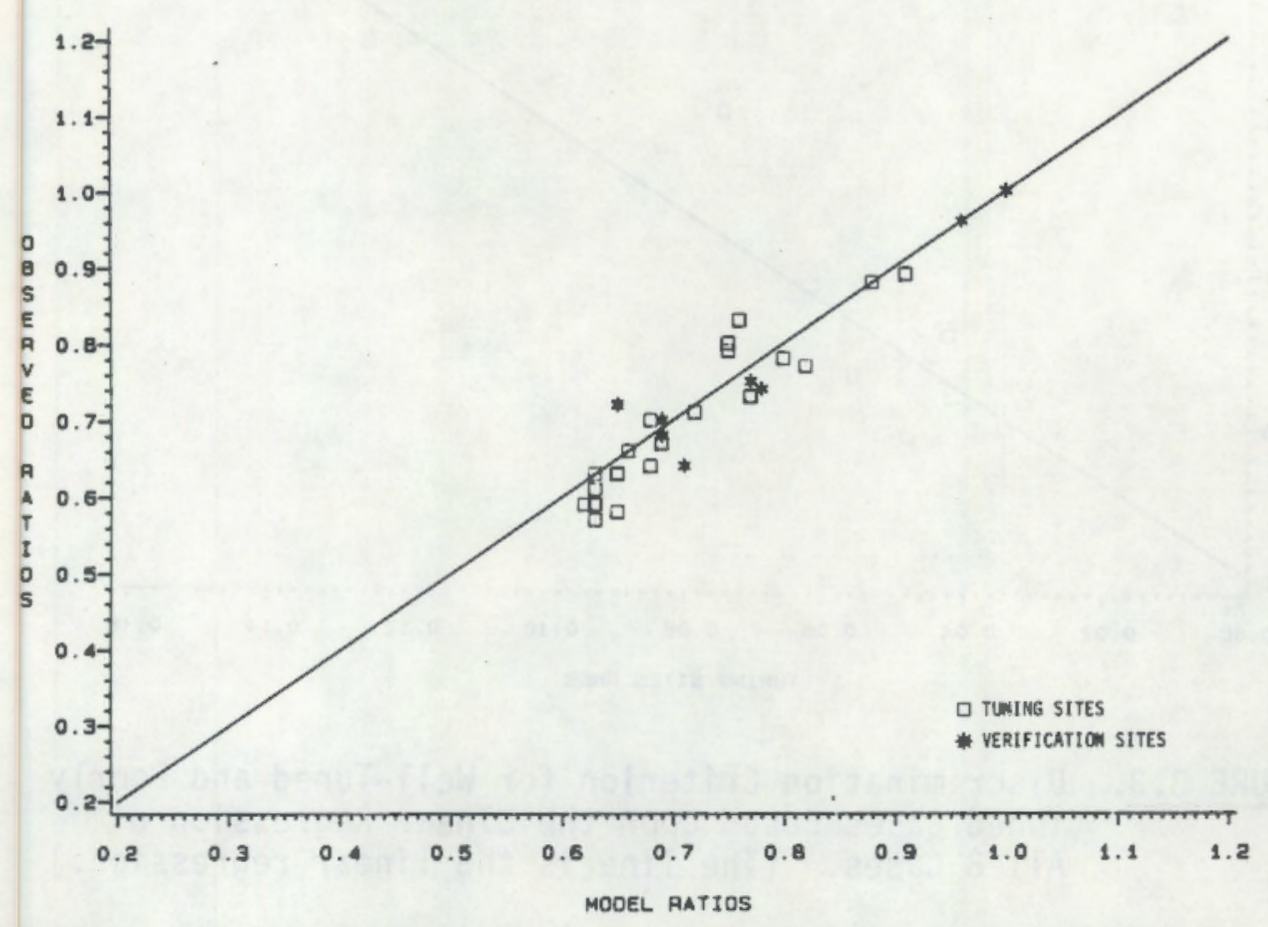

FIGURE 3.2. Tuning and Verification Site Observed Versus Modeled Wind-Speed Ratios for the Six Well-Tuned Cases

Explanations for the poorer performance of the tuning procedure for Cases $4 A$ and $4 B$ are still being explored; however, it is important to note that cases of poor tuning results can be identified during the tuning procedure to warn the user that the results of a particular model run may not be accurate. For example, in Figure 3.3 the correlation between tuning site RMSEs and verification site RMSEs demonstrates that, for the 8 cases examined, the tuning site RMSE of about 0.06 can be used to discriminate between good and poor model results. For the majority of cases examined, the flow model results were good to excellent.

To further illustrate the differences between expected (good) model performance and poor performance, scatter plots of wind-speed ratios are presented 


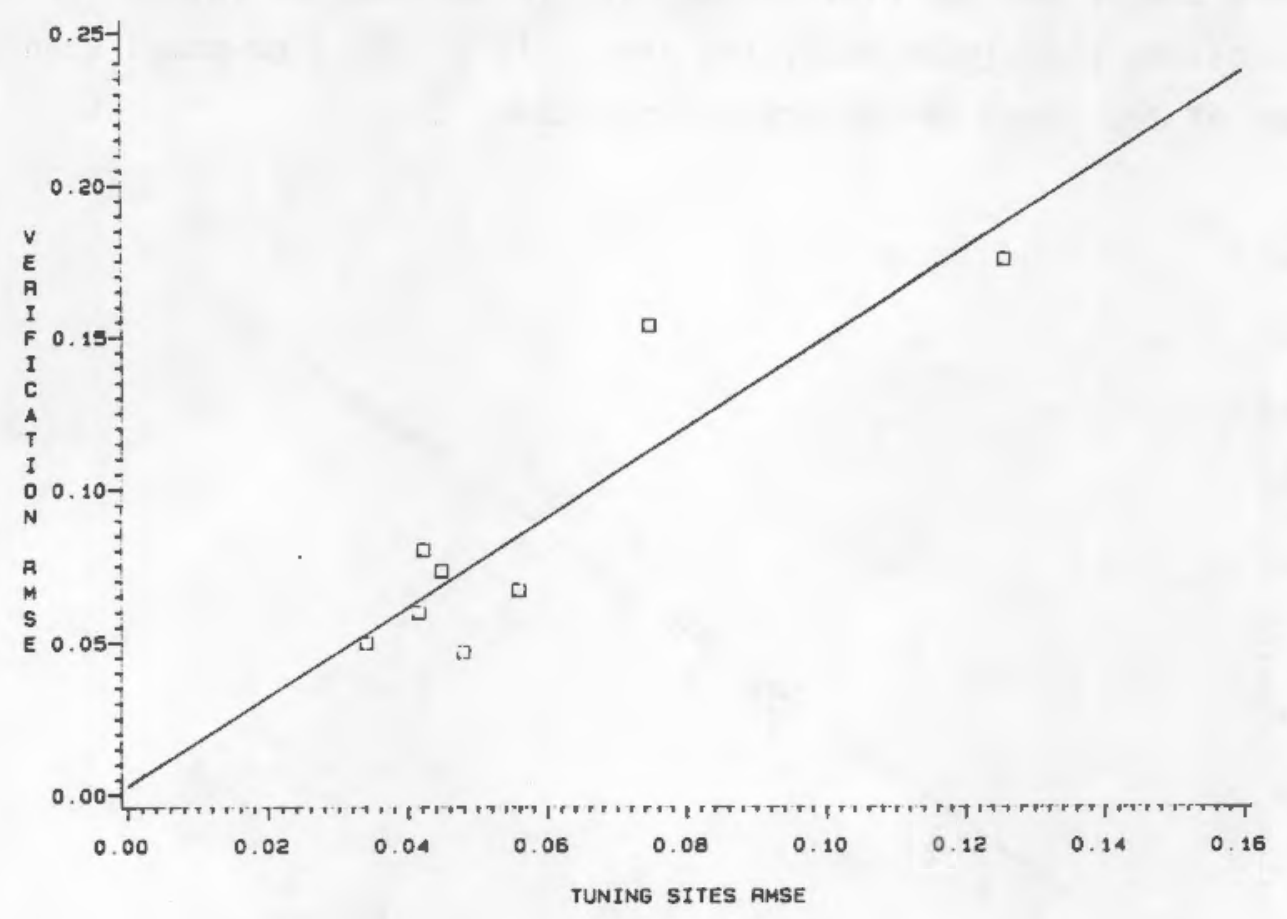

FIGURE 3.3. Discrimination Criterion for Well-Tuned and Poorly Tuned Cases Based Upon the Linear Regression of

Al1 8 Cases. (The line is the linear regression.)

in Figures 3.4 and 3.5, respectively, for a typically well-tuned case (Case $3 A$ ) and a poorly tuned case (Case 4A).

It is noteworthy that the flow model was poorly tuned only in cases where the winds were light to moderate (i.e., 10 to $20 \mathrm{mph}$ ) over the area of interest. Even when the model was well tuned and performed well (as in Figure 3.4), at the lower wind speeds the model tended to overpredict the ratios. For example, in Figure 3.4 calculated ratios between 0.5 and 0.7 were about $10 \%$ too high. The overprediction may not be due solely to the assumption of mass consistency. This effect could be partially due to the nature of the objective function (the root mean square error) that is minimized during the tuning process. The squaring of errors tends to weight the larger errors occurring at higher wind speeds more heavily than relatively smaller errors at the lower wind speeds. Consequently, the model tuning is biased toward the higher wind speeds. 


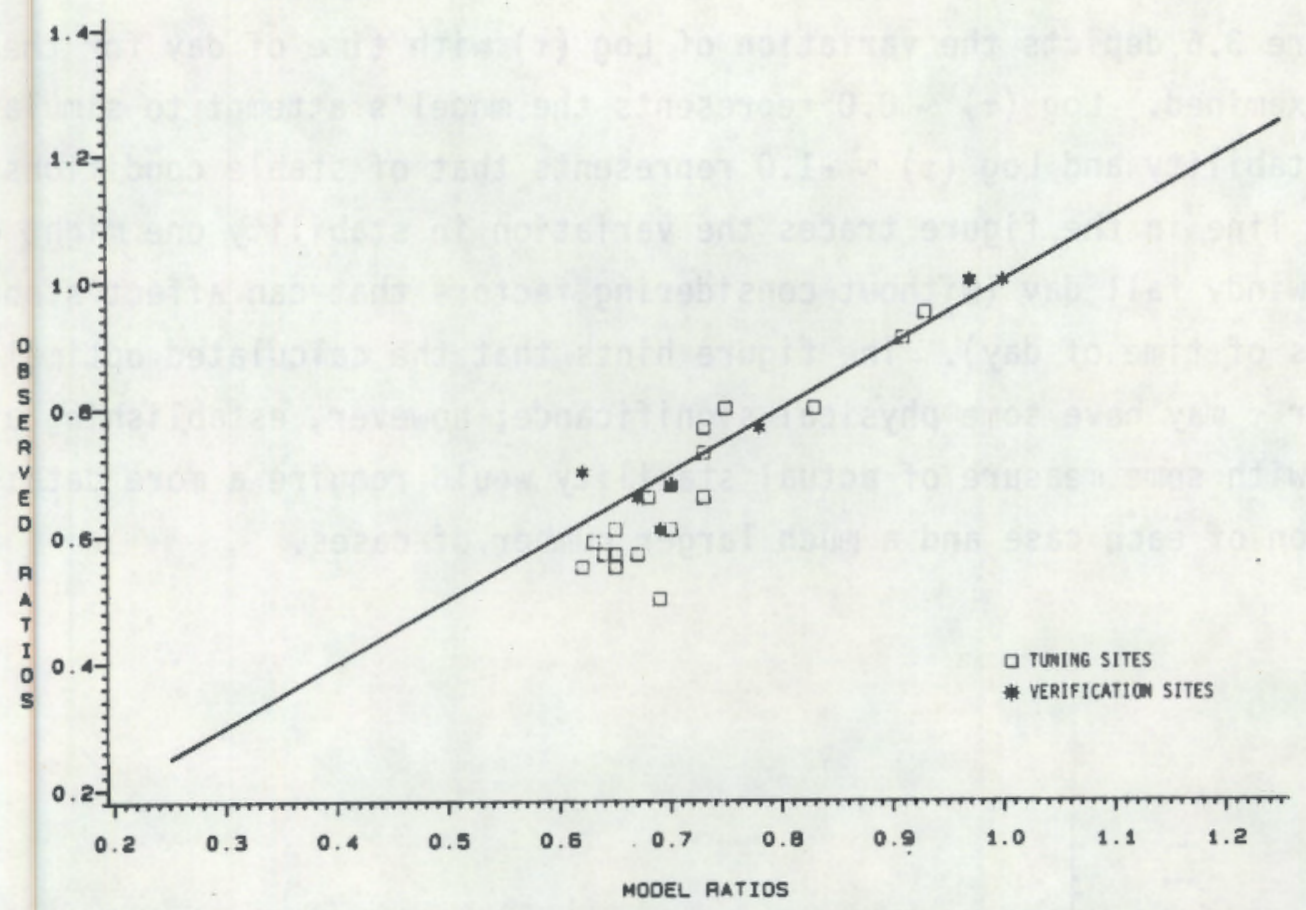

FIGURE 3.4. Typical Well-Tuned Flow Model Results (Case 3A)

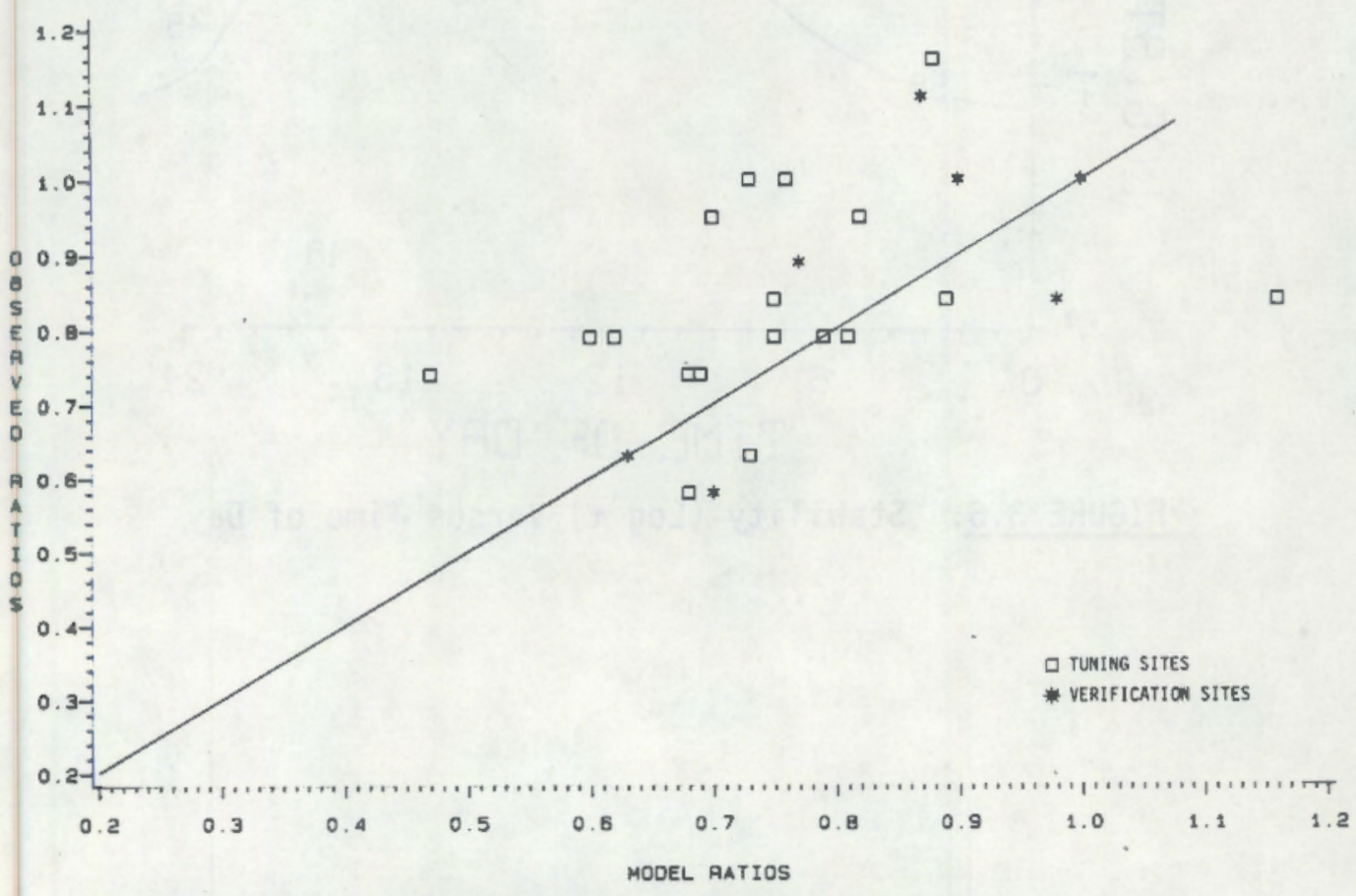

FIGURE 3.5. A Typical Case Demonstrating Poorly Tuned Flow Model Results (Case 4A) 
Figure 3.6 depicts the variation of $\log (\tau)$ with time of day for the 8 cases examined. $\log (\tau) \sim 0.0$ represents the model's attempt to simulate neutral stability and $\log (\tau) \sim-1.0$ represents that of stable conditions. The solid line in the figure traces the variation in stability one might expect during a windy fall day (without considering factors that can affect stability regardless of time of day). The figure hints that the calculated optimal values for $\tau$ may have some physical significance; however, establishing a relationship with some measure of actual stability would require a more detailed examination of each case and a much larger number of cases.

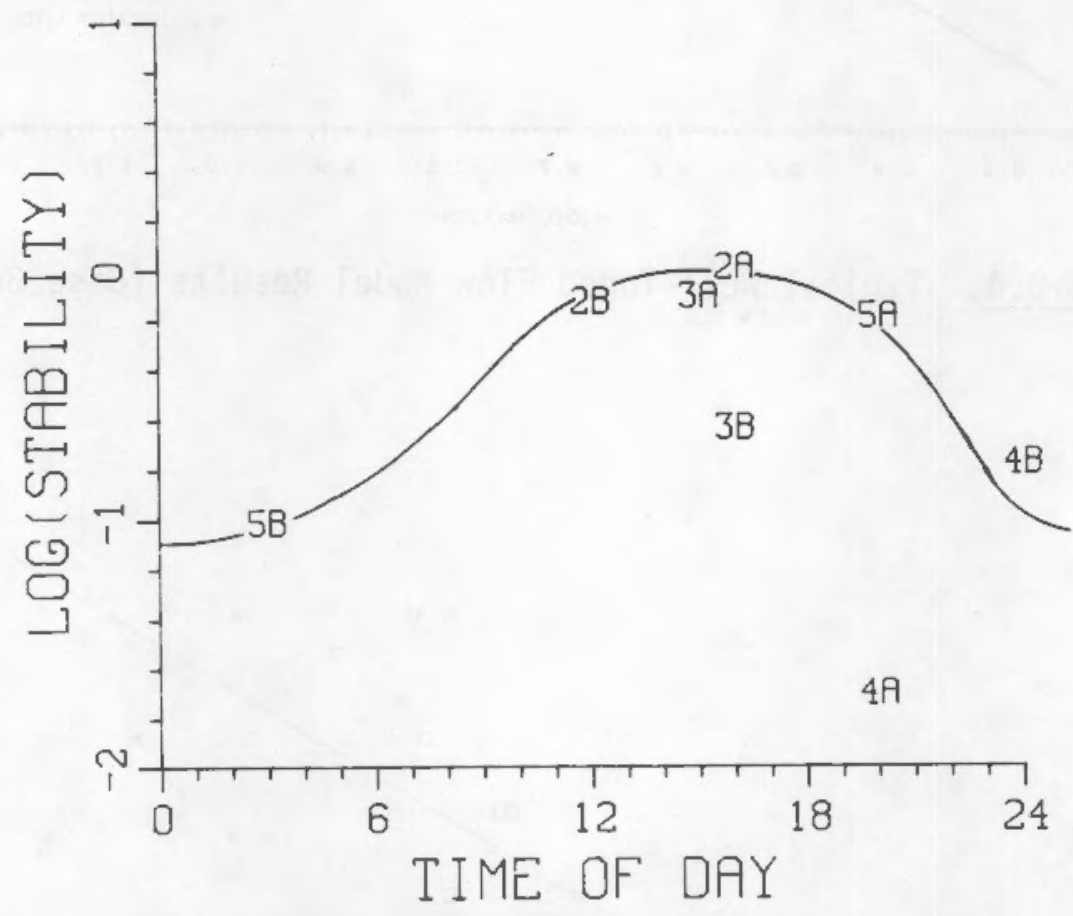

FIGURE 3.6. Stability $(\log \tau)$ Versus Time of Day 


\subsection{FURTHER RESEARCH}

The results presented in Section 3 are promising and suggest that numerical modeling can play a useful role in micrositing. Because the model was verified using only 8 data sets, there is not yet enough evidence to establish the model's reliability. Much more testing is necessary.

Further testing should be targeted at resolving the major uncertainty: Will the model perform well over a wide range of wind speeds and when applied to many different regions of complex terrain? Testing designed to investigate this would require large data sets obtained from spatially dense wind measurement programs undertaken at different places. Model performance can be gauged by the comparison of model results to the observations.

It is of particular importance to determine the range of wind speeds over which the model performs well. The results of Section 3 indicate that poor results sometimes occur for low wind speeds. This is physically plausible since physical factors aside from nondivergence assume a more dominant role at lower speeds. Unfortunately, the results achieved to date are too limited to permit a lower bound on the wind speed range to be established. The value of this bound is critical since if it is significantly greater than typical turbine cut-in speeds, some of the usefulness of the model will be lost.

Also of importance is the number of wind observations required for model initialization. Acceptable results were achieved for most cases presented in this report by using from 6 to 8 stations. It is not known if results of similar accuracy will still occur if the number of initialization stations is reduced. Also, the poor results (of Cases $4 A$ and $4 B$ ) may be improved by using more stations. An additional goal of testing is then to establish guidelines on the initialization requirements depending upon the wind speed and other conditions. The use of wind direction at all tuning sites in addition to wind speed may enhance the results or reduce the number of initialization stations; this should also be investigated. 


\subsection{REFERENCES}

Kitada, T., A. Kaki, H. Ueda, and L. K. Peters. 1983. "Estimation of Vertical Air Motion from Limited Horizontal Wind Data - A Numerical Experiment." Atmospheric Environment, 17:2181-2192.

Kuester, J. L., and J. H. Mize. 1973. Dptimization Techniques with Fortran. McGraw-Hill, New York, New York.

Sherman, C. A. 1978. "A Mass-Consistent Model for Wind Fields over Complex Terrain." J. Appl. Meteor., 17:312-319.

Traci, R. M., G. T. Phillips, and P. C. Patnaik. 1978. Developing a Site Selection Methodology for Wind Energy Conversion Sys tems. DOE/ET/20280-3, National Technical Information Service, Springfield, Virginia. 


\section{APPENDIX}

MODEL VERIFICATION RESULTS FOR EIGHT WIND CASES EXAMINED 


\section{APPENDIX \\ MODEL VERIFICATION RESULTS FOR EIGHT WIND CASES EXAMINED}

The following eight figures are scatter plots of model-calculated versus observed wind speed ratios for both the tuning and verification sites listed in Table 3.1 in the main body of the report. All ratios are calculated using Site 1 (in Table 3.1) as the reference site (denominator). The eight cases are those described in Table 3.1 . 


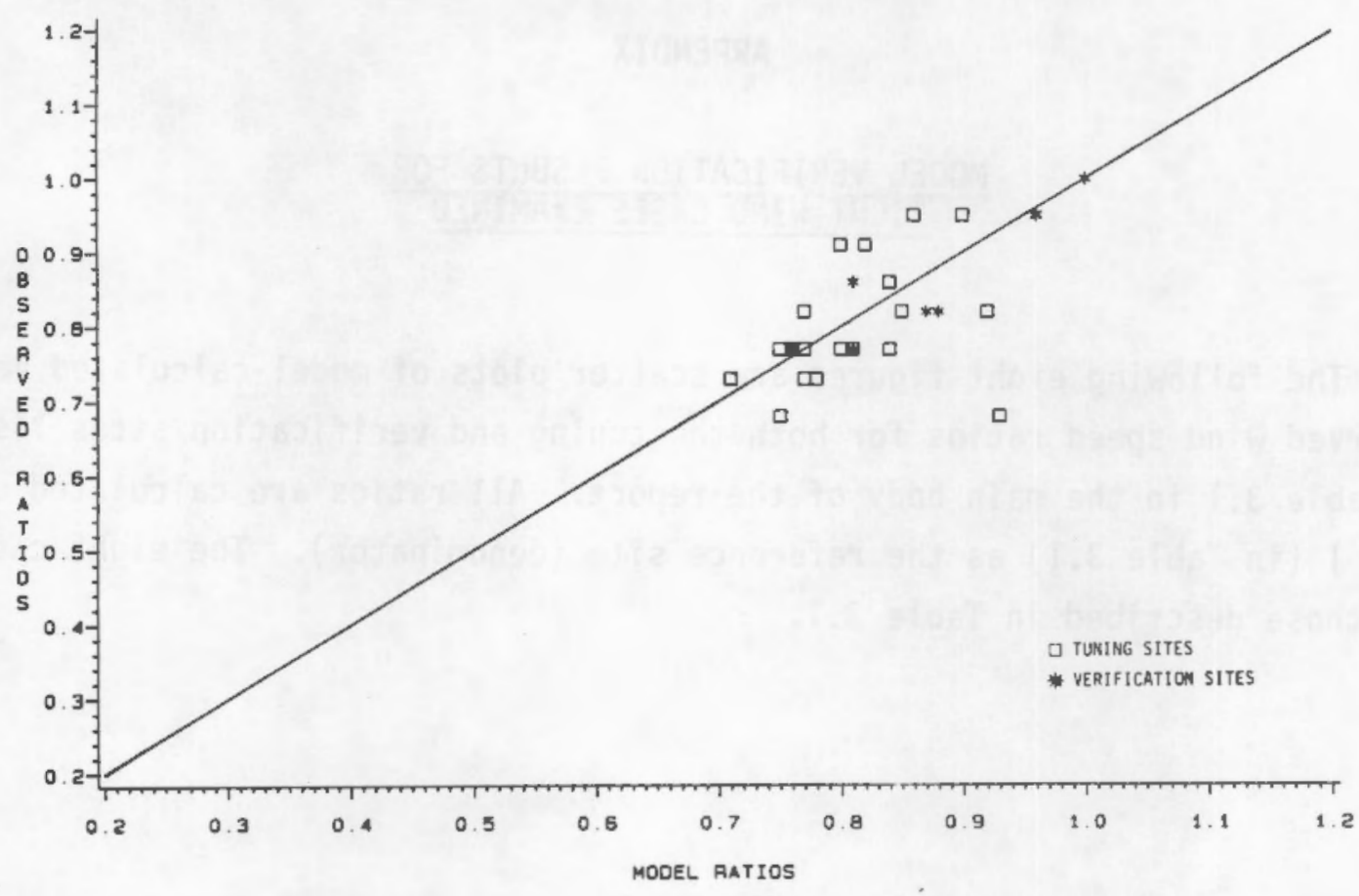

FIGURE A.1. Scatter Plot of Observed Versus Model-Calculated Wind Speed Ratios for Case $2 \mathrm{~A}$

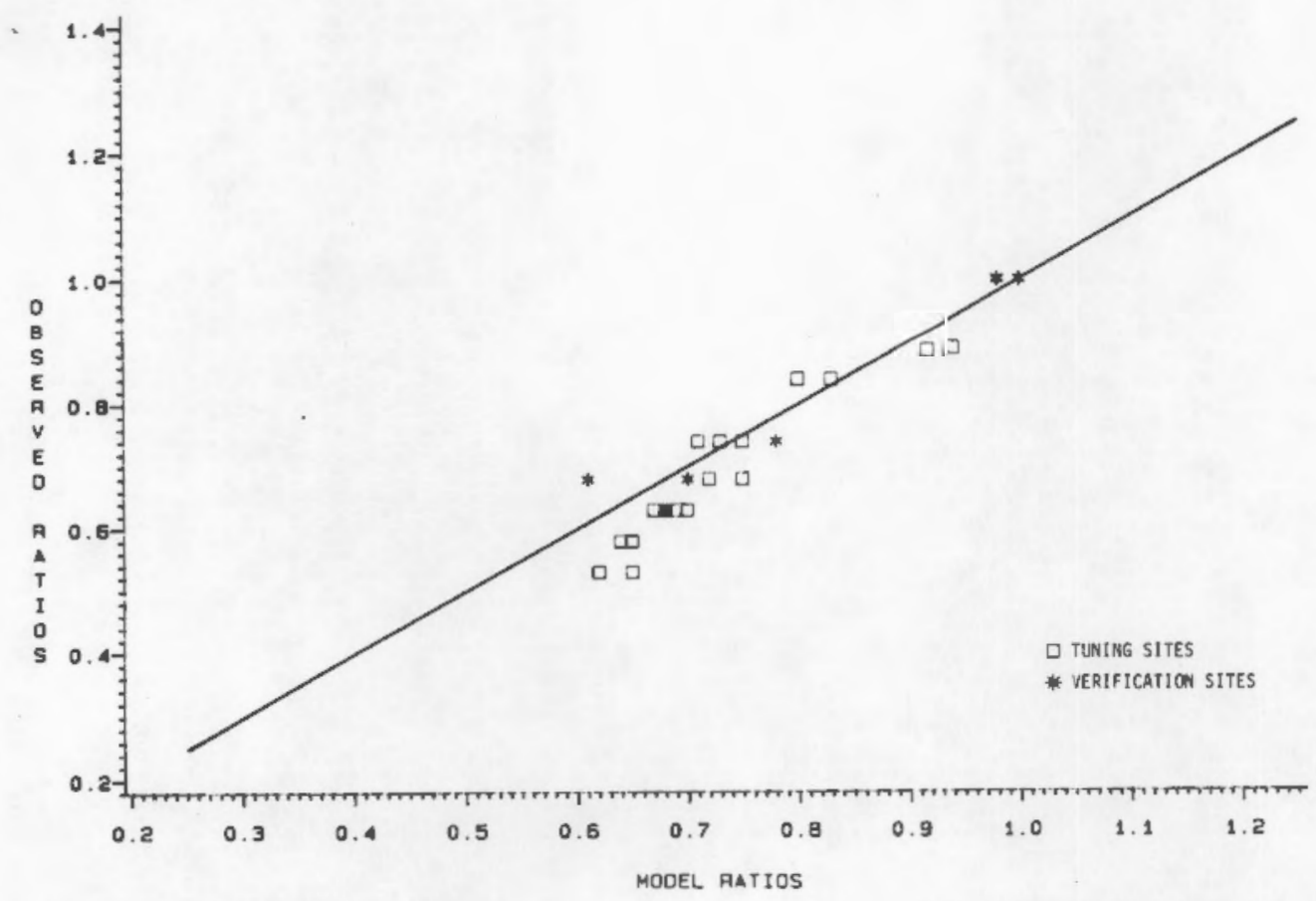

FIGURE A.2. Scatter Plot of Observed Versus Model-Calculated Wind Speed Ratios for Case 2B 


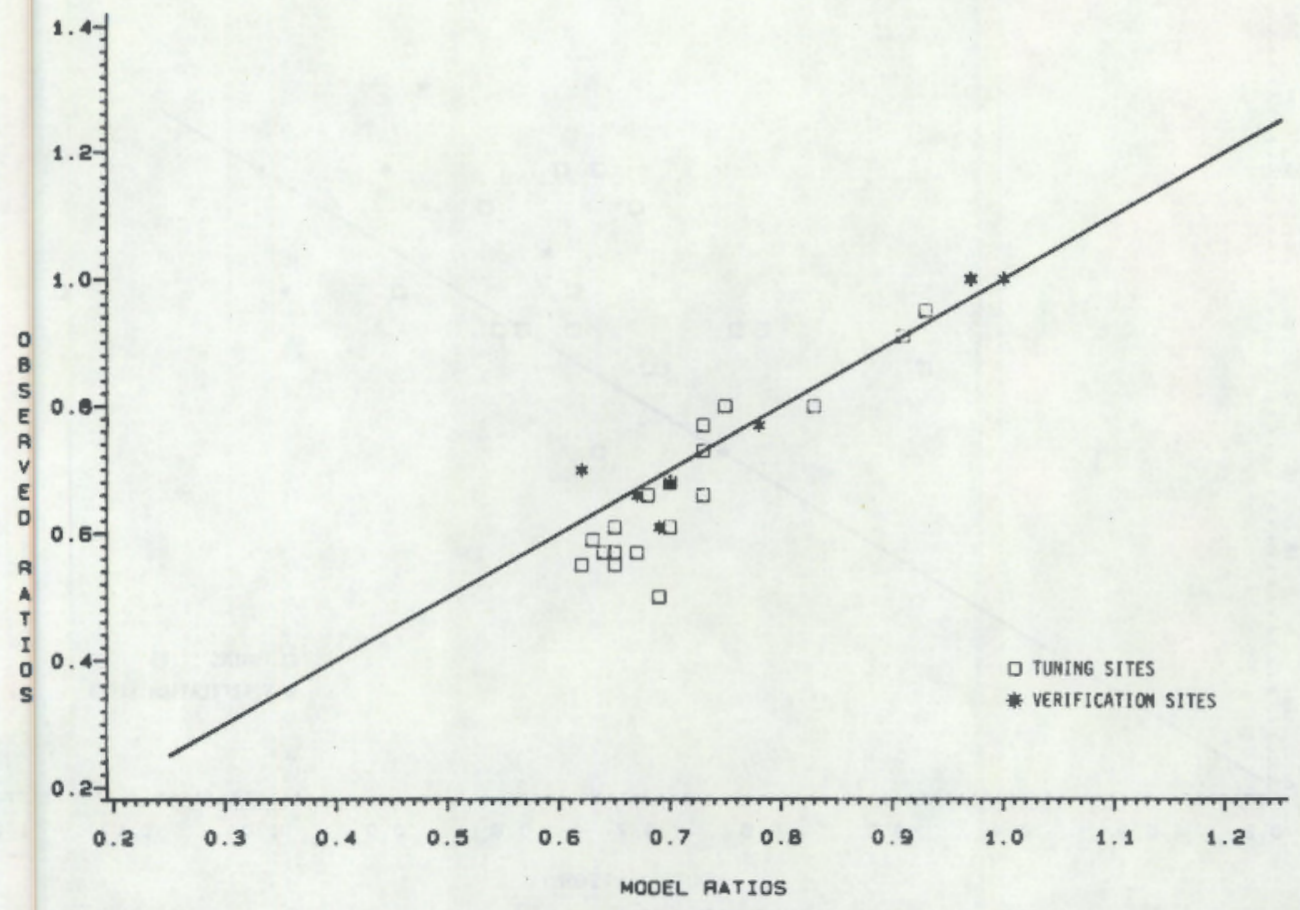

FIGURE A.3. Scatter Plot of Observed Versus Model-Calculated Wind Speed Ratios for Case $3 A$

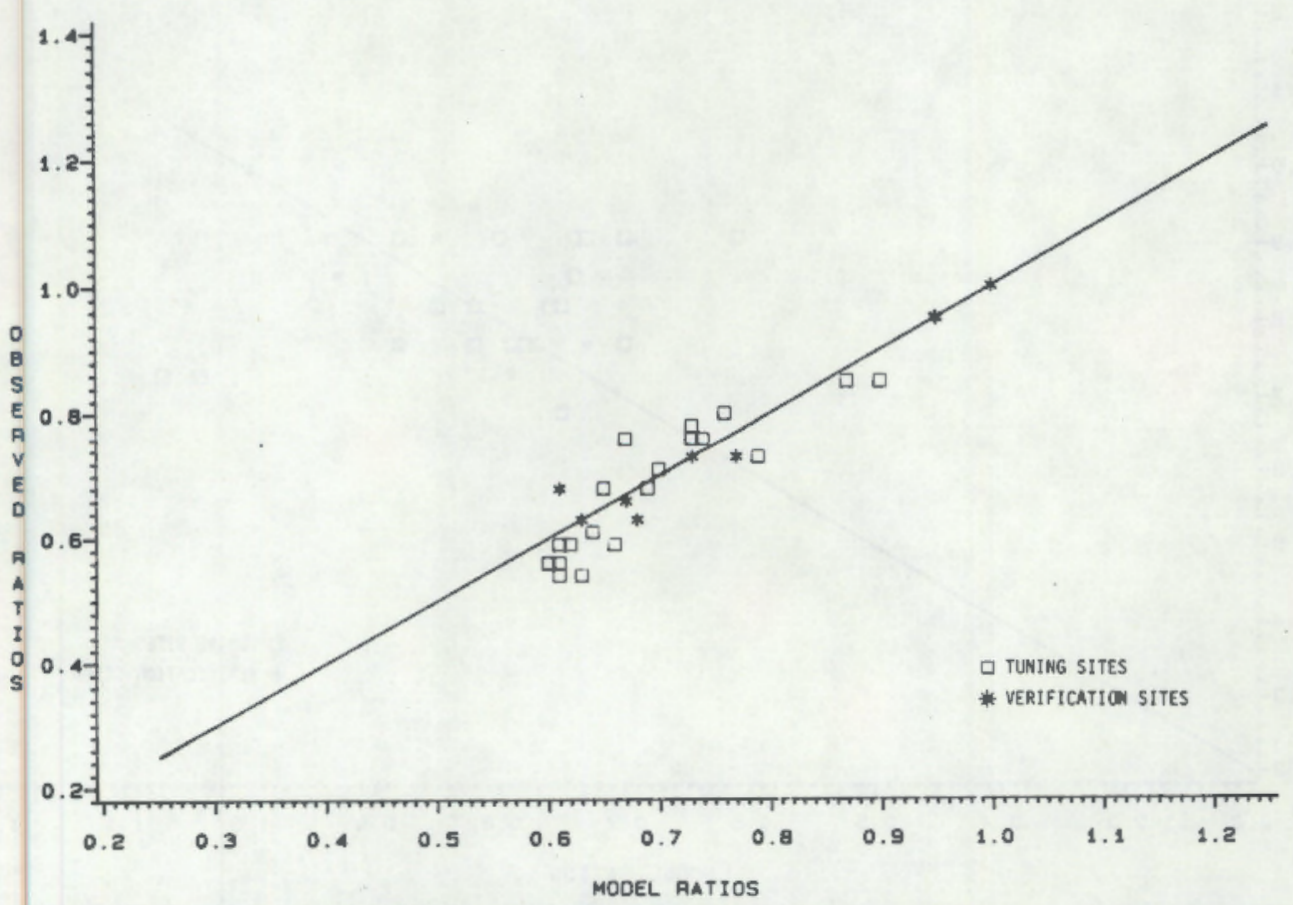

FIGURE A.4. Scatter Plot of Observed Versus Model-Calculated Wind Speed Ratios for Case 3B 


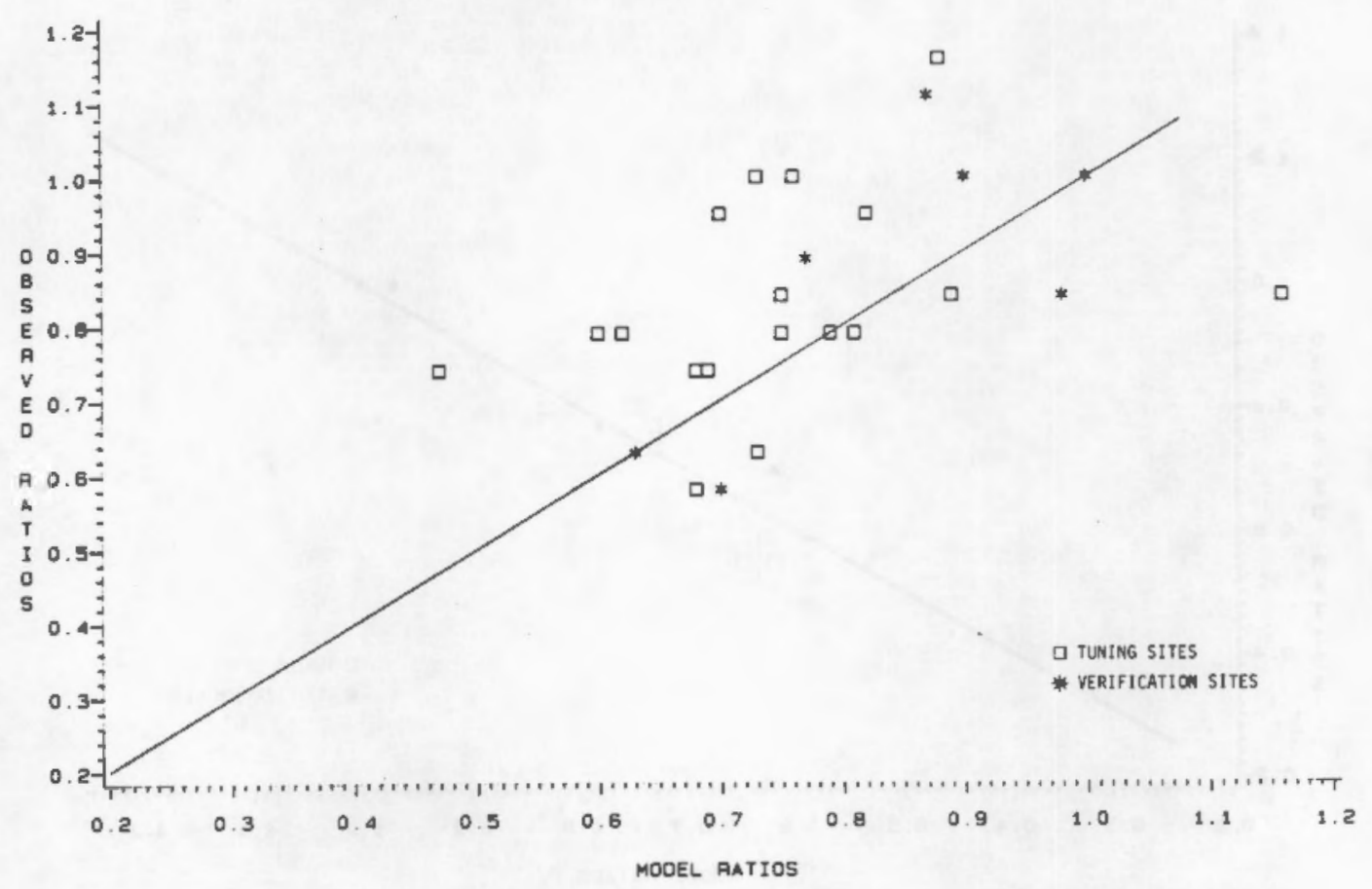

FIGURE A.5. Scatter Plot of Observed Versus Model-Calculated Wind Speed Ratios for Case 4A

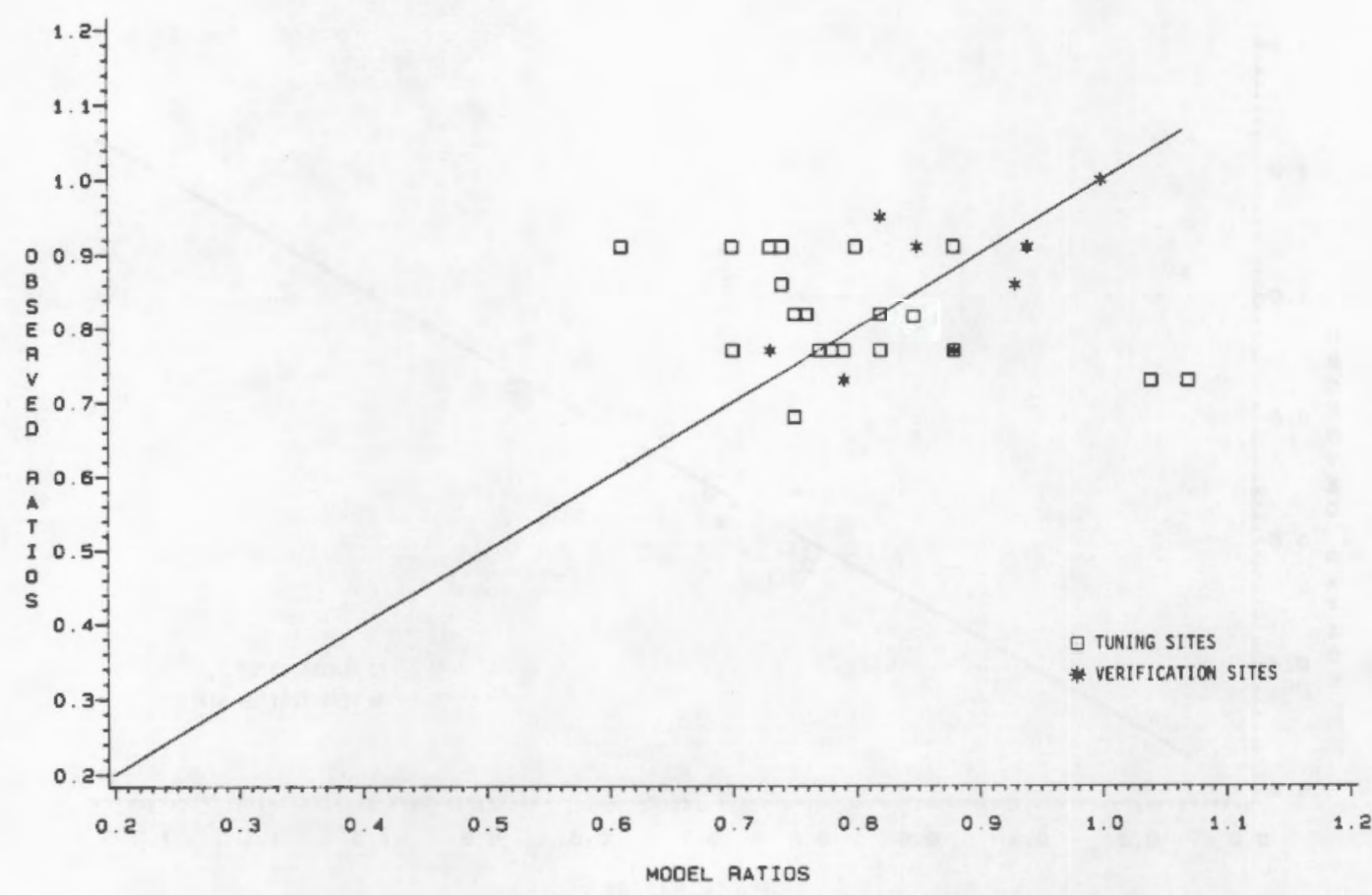

FIGURE A.6. Scatter Plot of Observed Versus Mode1-Calculated Wind Speed Ratios for Case 4B 


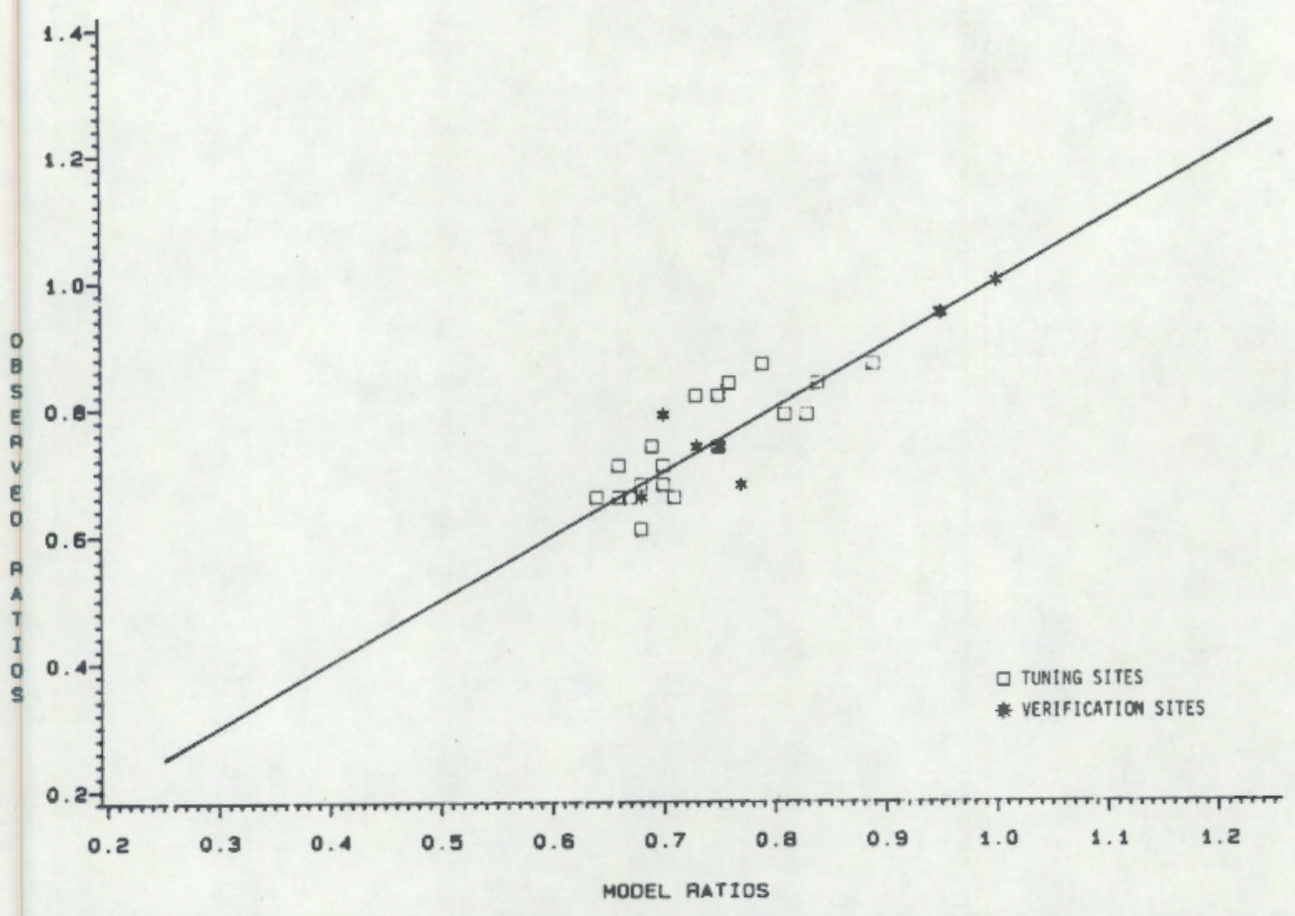

FIGURE A.7. Scatter Plot of Observed Versus Model-Calculated Wind Speed Ratios for Case 5A

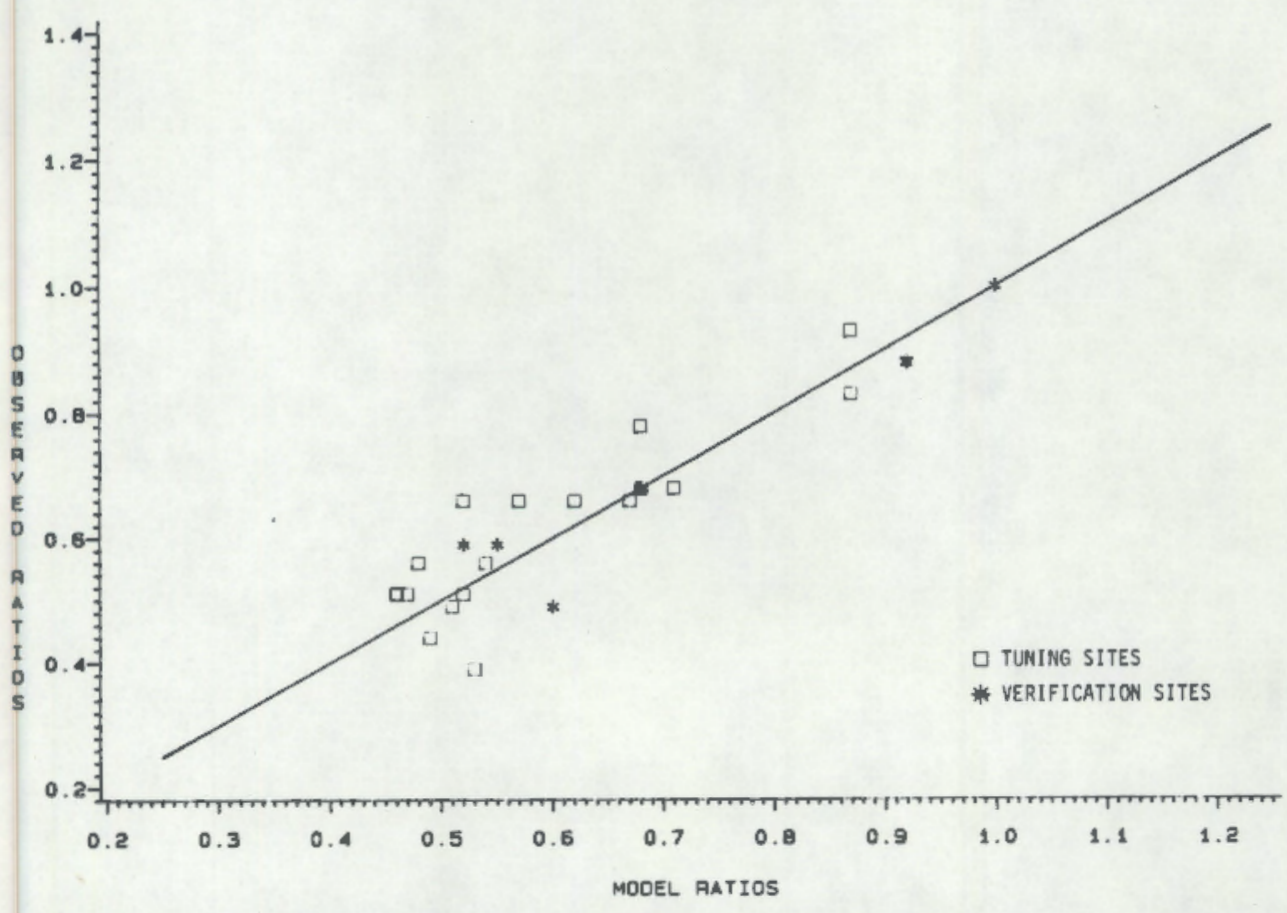

FIGURE A.8. Scatter Plot of Observed Versus Model-Calculated Wind Speed Ratios for Case 5B 



\section{DISTRIBUTION}

No. of

Copies

OFFSITE

Carl Aspliden

Battelle Memorial Institute

Washington Office

2030 M Street NW

Washington, DC 20036

J. Cadogan

Department of Energy

Wind Energy Technology Division

1000 Independence Avenue

Forresta1 Building, Room 5H048

Washington, DC 20585

\section{0 . F. Ancona}

Department of Energy

Wind Energy Technology Division

1000 Independence Avenue

Forrestal Building, Room $5 \mathrm{HO} 48$

Washington, DC 20585

G. P. Tennyson

Department of Energy

Albuquerque Operations office

P.0. Box 5400

Albuquerque, NM 87110

30 DOE Technical Information Center

Peter Lissaman

Aerovironment, Inc.

145 Vista Avenue

Pasadena, CA 91107

Tom Gray

American Wind Energy Association 1516 King Street

Alexandria, VA 22314

W. A. Vachon

P.0. Box 149

Manchester, MA 01944
No. of

Copies

Mike Bovarnick

Boeing Aerospace Corporation

P.0. Box 3999

Seattle, WA 98124

Wayne Wiesner

Boeing Aerospace Corporation

P.0. Box 3999

Seattle, WA 98124

Gary Miller

Boeing Aerospace Corporation

P.0. Box 3999

Seattle, WA 98124

Mike Rees

Boeing Aerospace Corporation

P0 Box 3999

Seattle, WA 98124

Don Fries

Boeing Aerospace Corporation

P.0. Box 3999

Seattle, WA 98124

Dick Hacker

Boeing Aerospace Corporation

P.0. Box 3999

Seattle, WA 98124

Ron Holeman

Bonneville Power Administration

Generation Engineering

P.0. Box 3621

Portiand, OR 97208

S. J. Hightower

Bureau of Reclamation

Denver Federal Center

Building 67, Code 254

Denver, C0 80225

Willi Sadeh

Department of Civil Engineering

Colorado State University

Fort Collins, C0 80523 
No. of

Copies

V. A. Sandborn

Department of Civil

Engineering

Colorado State University

Fort Collins, $\mathrm{CO} 80523$

Dr. Edgar DeMeo

Electric Power Research

Institute

3412 Hillview Avenue

Palo Alto, CA 94303

Frank Goodman, Jr.

Electric Power Research

Institute

3412 Hiliview Avenue

Palo Alto, CA 94303

R. L. George

TERRA Sciences, Inc.

7555 W. 10th Avenue

Lakewood, CO 80214

Tom Hiester

Flowind Corporation

1183 Quarry Lane

Pleasanton, CA 94566

J. M. Kos

Hamilton Standard

Bradley Field Road

Windsor Locks, CT 06096

Eugene Di Valentin

Hamil ton Standard

Bradley Field Road

Windsor Locks, CT 06096

Glid Doman

Hamilton Standard

Bradiey Field Road

Windsor Locks, CT 06096

G. L. Park

Department of Electrical Engineering

Michigan State University

East Lansing, MI 48824
No. of

Copies

R. B. Schlueter

Department of Electrical

Engineering

Michigan State University

East Lansing, MI 48824

W. D. Johnston

Hawaiian Electric Company, Inc.

P.0. Box 2750

Honolulu, HI 96840

David Spera

NASA/Lewis Research Center

21000 Brookpark Road

Cleveland, $\mathrm{OH} 44135$

Phillip French

NASA Scientific and Technica? Information Facility

P.0. Box 8757

Ba) timore/Washington International Airport

Baitimore, MD 21240

J. C. Kaima]

National Oceanic and Atmospheric Administration/Environmenta 1 Research Laboratories/Wave Propagation Laboratory

3000 Marine Street

Boulder, CO 80302

G. M. Gregorek

Aeronautics and Astronautics

Research Lab

Ohio State University

2300 W. Case Road

Columbus , $\mathrm{OH} 43220$

Peter M. Moretti

OKlahoma State University

Mechanical and Aerospace

Engineering

Engineering North 218

Stillwater, OK 74074 
No. of

Copies

Robert Wilson

Department of Mechanical

Engineering

Oregon State University

Corvaliis, OR 97331

Dr. H. A. Panofsky

6222 Agee Street \#5

San Diego, CA 92122

3. Dutton

Department of Meteorology

Pennsylvania State University

University Park, PA 16902

Andrew Trenka

Solar Energy Research Institute

Rocky Flats

P.0. Box 464

Golden, C0 80401

P. Klimas

Sandia Laboratories

Division 5443, P.0. Box 5800

Albuquerque, NM 87115

Robert Noun

Solar Energy Research Institute 1617 Cole Boulevard

Golden, CO 80401

Robert Thresher

Solar Energy Research Institute

1617 Cole Boulevard

Golden, C0 80401

Sherman M. Chan

Systems Control, Inc.

1801 Page Mill Road

P.0. Box 10025

Palo Alto, CA 94303

R. H. Kirchhoff

Department of Mechanical

Engineering

University of Massachusetts

Amherst, MA 01003
No. of

Copies

Ear\} L. Davis

U.S. Windpower, Inc.

2305 S. Vasco Road

Livernore, CA 94550

H. Tieleman

Department of Engineering Science \& Mechanics

Virginia Polytechnic Institute and State University

Blacksburg, VA 24061

Susan Hosch

Washington State Energy Office

$400 \mathrm{E}$. Union Avenue, 1st Floor

Olympia, WA 98504

Farrell Smith Seiler

Wind Energy Report

Box 14 - 104 S. Village Avenue

Rockvilie Centre, NY 11571

\section{FOREIGN}

Leif Kristensen

Department of Physics

Ris $\varnothing$ National Laboratory

4000 Roskilde

DENMARK

Per Lundsager

Ris $\varnothing$ National Laboratory

P.0. Box 49

DK-4000 Roskilde

DENMARK

Dr. M. B. Anderson

Sir Robert McAlpine \& Sons, Ltd. 40 Bernard Street London WCIN ILG ENGLAND

Dr. D. Wilson

Cavendish Laboratory

Madingley Road

Cambridge CB3 OHE

ENGLAND 
No. of

Copies

D. Lindley

Taylor Woodrow Construction, Ltd.

Taywood House

345 Ruis? ip Road

Southal1

Middlesex UBI 2QX

ENGLAND

Dr. Neil Cherry

Lincoln College

Canterbury

NEW ZEALAND

\section{ONSITE}

DOE Richland Operations Office

D. R. Segna

39 Pacific Northwest Laboratory

J. C. Barnard (5)

J. W. Buck

J. R. Connell

D. W. Dragnich

C. E. Elderkin

D. L. Elliott

J. M. Hales

P. C. Hays

M. E. Hinchee

B. D. Holst

A. H. Miller

V. R. Morris

E. L. Owczarski

D. C. Powe 11

J. A. Stottlemyre

T. K. Thompson

R. E. Wildung

H. L. Wegley (5)

L. L. Wende 11

Technical Information Files (5)

Publishing Coordination (2)

WCPE Program Dffice (5) 